\title{
Analisis Pengaruh Media Bahan Bekas Terhadap Keterampilan Motorik Halus pada Anak Usia 5-6 Tahun di PAUD Al Hikmah
}

\author{
Baiq Nuning Sudiarni, I Made Gunawan* \\ Fakultas Ilmu Pendidikan dan Psikologi, UNDIKMA \\ *Corresponding Author. Email: imadegunawan@undikma.ac.id
}

\begin{abstract}
This study aims to analyze the effect of used material media on fine motor skills of early childhood. This research uses quantitative research. The sample of this study were 15 children aged 5-6 years in class B PAUD Al Hikmah, with a purposive sampling technique. The research instrument used an observation sheet in the form of an assessment rubric. The data analysis technique used a simple linear regression test. The results of this study concluded that there was an effect of used material media on fine motor skills of early childhood in PAUD Al Hikmah.
\end{abstract}

\begin{abstract}
Abstrak: Penelitian ini bertujuan untuk menganalisis pengaruh media bahan bekas terhadap keterampilan motorik halus anak usia dini. Penelitian ini menggunakan penelitian kuantitatif. Sampel penelitian ini adalah anak usia 5-6 tahun di kelas B PAUD Al Hikmah berjumlah 15 diambil dengan tehnik purposive sampling. Instrument penelitian menggunakan lembar observasi berupa rubrik penilaian. Teknik analisis data menggunakan uji regresi linier sederhana. Hasil penelitian ini menyimpulkan bahwa terdapat pengaruh media bahan bekas terhadap keterampilan motorik halus anak usia dini di PAUD Al Hikmah.
\end{abstract}

\author{
Article History \\ Received: 14-01-2021 \\ Revised: 06-03-2021 \\ Accepted: 11-04-2021 \\ Published: 05-10-2021 \\ Key Words: \\ Material Media, Fine \\ Motor Skills, Early \\ Childhood.
}

\section{Sejarah Artikel}

Diterima: 14-01-2021

Direvisi: 06-03-2021

Disetujui: 11-04-2021

Diterbitkan: 05-10-2021

\section{Kata Kunci: \\ Media Bahan Bekas, \\ Motorik Halus, Anak \\ Usia Dini .}

How to Cite: Sudiarni, B., \& Gunawan, I. (2021). Analisis Pengaruh Media Bahan Bekas Terhadap Keterampilan Motorik Halus pada Anak Usia 5-6 Tahun di PAUD Al Hikmah. Jurnal Paedagogy, 8(4), 594599. doi:https://doi.org/10.33394/jp.v8i4.3409

\section{Pendahuluan}

Pendidikan anak usia dini merupakan suatu upaya pembinaan yang di tujukan kepada anak usia dini sampai usia enam tahun dengan memberikan stimulasi terhadap seluruh aspek perkembangan anak agar optimal. Selain itu, pendidikan anak usia dini bertujuan untuk mempersiapkan anak untuk memasuki jenjang pendidikan yang lebih lanjut yang di selenggarakan melalui jenjang pendidikan formal, informal dan nonformal. Pendidikan anak usia dini dilaksanakan sesuai dengan karakteristik dan tingkat perkembangan anak sehingga proses pendidikan tidak terstruktur, informal, emergen dan responsif terhadap perbedaan individual anak serta melalui aktivitas berlangsung suasana bermain (Kemdikbud, 2016).

Upaya pembinaan di pendidikan anak usia dini dapat di lakukan melalui pengembangan program pembelajaran yang tepat. Pengembangan program pembelajaran di pendidikan anak usia dini tersebut meliputi penggunaan alat permainan edukatif/media, model, teknik, strategi dan metode dalam pembelajaran, serta indikator yang akan dicapai dalam pembelajaran. Selain itu, dalam pelaksanaan program pembelajaran tersebut harus di laksanakan dengan suasana yang menyenangkan bagi anak, karena pertumbuhan dan perkembangan anak tergantung pada pengasuhan, pendidikan dan pembelajaran yang diberikan (Pamilu dalam Nurmayani, Rizka, Maskun, 2018; Alit Suarti, 2020). 
Pendidikan anak usia dini pada dasarnya adalah pendidikan yang di tujukan untuk memfasilitasi pertumbuhan dan perkembangan anak secara menyeluruh yang menitik beratkan pada seluruh aspek perkembangan, baik dari aspek nilai agama dan moral, fisik motorik, bahasa, kognitif, sosial emosional dan seni. Setiap aspek perkembangan individu, baik sosial, emosi, satu sama lainnya saling mempengaruhi (Rabiah \& Tamba, 2014: Endriani, 2015). Oleh karena itu, pada kegiatan pembelajaran di pendidikan anak usia dini hendaknya mampu untuk menstimulasi seluruh aspek perkembangan.

Salah satu aspek perkembangan anak yang harus dikembangkan yaitu aspek perkembangan motorik halus. Motorik halus merupakan suatu gerak fisik yang melibatkan otot-otot kecil dengan melibatkan bagian-bagian tertentu, seperti koordinasi antara mata dengan tangan yang baik. Motorik halus juga di sebut gerakan halus, karena hanya melibatkan otot-otot kecil dan bagian-bagian tertentu (Gunarti, 2010). Motorik halus mencakup beberapa kegiatan, yaitu kegiatan menggenggam, membentuk, menggambar, menempel, dan menjiplak. Kegiatan tersebut dapat di lakukan melalui berbagai media dan permainan yang menyenangkan, melalui kegiatan tersebut diharapkan keterampilan motorik halus anak dapat berkembang. Hasnida (2014) menyatakan bahwa motorik halus adalah gerakan yang menggunakan otot- otot halus atau sebagian anggota tubuh tertentu yang di pengaruhi oleh kesempatan untuk belajar dan berlatih. Pengembangan motorik halus di pendidikan anak usia dini tidak terlepas dari peran guru sebagai pendidik, dalam proses menstimulasi keterampilan motorik halus khususnya dalam koordinasi antara mata dan tangan, dalam kegiatan pembelajaran guru hanya memberikan kegiatan berupa kegiatan menggambar, mewarnai dan menulis. Sedangkan untuk kegiatan menempel, dan meniru bentuk masih jarang untuk dilaksanakan.

Pada anak usia 5-6 tahun, stimulasi terhadap keterampilan motorik halus anak sangat diperlukan agar mereka dapat tumbuh dan berkembang secara optimal (jamaris, 2013). Selain itu, stimulasi yang diberikan saat masa usia dini dapat mempersiapkan anak untuk memasuki jenjang pendidikan yang lebih lanjut. Stimulasi perkembangan motorik halus dapat dilaksanakan melalui kegiatan bermain, dengan kegiatan bermain diharapkan keterampilan motorik halus dapat berkembang dengan optimal.

Berdasarkan hasil survey awal di PAUD Al Hikmah Kebon Orong, Desa Dasan Baru Kecamatan Kediri Kabupaten Lombok Barat, dalam pelaksanaan kegiatan pembelajaran terdapat beberapa anak pada kelompok B yang keterampilan motorik halusnya rendah. Keterampilan tersebut yaitu keterampilan dalam hal menggambar, mewarnai, dan meniru bentuk. Pada saat kegiatan menggambar, terdapat 5 dari 15 anak yang belum dapat menggambar objek secara rinci. Selain itu, ketika anak diberikan tugas untuk mewarnai, terdapat 7 anak yang hasil warnanya masih keluar garis. Kemudian ketika anak mendapat tugas untuk meniru bentuk yang telah di contohkan, anak juga masih kesulitan dalam menyelesaikannya. Namun saat menulis, hampir semua anak mampu menyelesaikannya dengan baik, hanya 4 anak yang belum mampu menyelesaikan tugas menulisnya. Kegiatan menulis tersebut berupa kegiatan menulis di buku paket yang berisi kotak-kotak satu halaman penuh. Jadi, anak diharuskan untuk menyelesaikan tugas tersebut hingga selesai.

Pada hakikatnya, pembelajaran di pendidikan anak usia dini di lakukan melalui bermain. Kegiatan bermain di pendidikan anak usia dini tentunya tidak terlepas dari media sebagai sarana dalam bermain. Media pembelajaran merupakan komponen penting dalam kegiatan pembelajaran. Media pembelajaran adalah alat yang dapat membantu proses belajar mengajar dan berfungsi untuk memperjelas makna pesan yang disampaikan, sehingga dapat 
mencapai tujuan pembelajaran dengan lebih baik dan sempurna (Kustandi \& Sutjipto dalam Surodiana, 2020; Selamet, 2020).

Banyak media pembelajaran yang dapat digunakan untuk kegiatan pembelajaran, namun tidak semua media tersebut cocok untuk mengajarkan semua materi pelajaran dan untuk semua anak. Media tersebut harus dipilih dengan cermat agar digunakan secara optimal dalam pembelajaran. Media pembelajaran yang tepat digunakan di pendidikan anak usia dini adalah media pembelajaran yang menarik dan menyenangkan bagi anak. Nurani dan Sujiono (2010) menyebutkan bahwa media pembelajaran dan sumber belajar dan bermain yang dapat digunakan oleh anak bersama guru merupakan salah satu faktor penting yang sangat mempengaruhi penguasaan anak terhadap materi yang diberikan. Melalui media dan sumber belajar inilah anak akan bereksplorasi dan bereksperimen dengan bahan yang ada.

Media bahan bekas adalah media pembelajaran yang bahannya bersumber dari bahan bekas. Media dengan bahan ini sangat mudah didapatkan karena bersumber dari bahan yang sudah tidak terpakai. Misalnya kardus bekas, sedotan, Koran bekas dan stik es. Bahan bekas ini sebagian besar adalah yang telah digunakan oleh anak. Menurut Iskandar (2006) bahan atau barang bekas yang di maksudkan adalah semua barang yang telah di pergunakan atau tidak di pakai lagi atau dapat di katakan sebagai barang yang telah di ambil bagian utamanya. Sedangkan menurut Nilawati (2010) bahan bekas yang biasanya di sebut sebagai sampah ini dapat berupa plastic, kaleng, kertas dan kain perca. Benda tersebut dapat di manfaatkan menjadi sebuah benda yang memiliki nilai tinggi.

Keberadaan barang bekas yang tidak terpakai sangat mudah di temukan di lingkungan sekitar. Bahan bekas ini kemudian dibuat sedemikian rupa sehingga menjadi sebuah media yang dapat digunakan dalam pembelajaran. Media ini dibuat sendiri oleh anak. Media yang dibuat sendiri oleh anak tentunya dapat menarik minat anak dalam proses pembelajaran dan diharapkan dengan bermain menggunakan media bahan bekas ini dapat meningkatkan keterampilan motorik halus anak. Keterampilan motorik halus merupakan keterampilan anak dalam mengkoordinasikan gerakan otot halus dari anggota tubuhnya dengan sangat baik. Keterampilan ini melibatkan koordinasi yang baik antara mata dantangan. Mahendra dalam Sumantri (2005) menjelaskan bahwa: Keterampilan motorik halus (fine motorskill) merupakan keterampilan-keterampilan yang memerlukan koordinasi mata dan tangan untuk mengontrol otot-otot kecil/halus untuk mencapai pelaksanaan keterampilan yang berhasil. Hal ini sejalan dengan pendapat Hurlock (2013) bahwa keterampilan motorik halus yaitu: Kemampuan menggunakan otot-otot halus yang melibatkan koordinasi antara mata dan tangan. Pengendalian otot tangan, bahu,dan pergelangan tangan meningkat dengan cepat selama masa kanak-kanak dan pada usia 12 tahun anak hampir mencapai tingkat kesempurnaan seperti orang dewasa. Adapun tujuan penelitian ini adalah untuk menganalisis pengaruh media bahan bekas terhadap keterampilan motorik halus anak usia 5-6 tahun di kelas B PAUD Al Hikmah Kediri.

\section{Metode Penelitian}

Metode yang digunakan dalam penelitian ini yaitu Pre-Experimental Designs. Menurut Agus Abdurahman (2013) metode eksperimen merupakan metode penelitian yang menguji hipotesis berbentuk hubungan sebab-akibat melalui pemanipulasian variable indepanden dan menguji perubahan yang diakibatkan oleh pemanipulasian tersebut. Penelitian ini menggunakan design penelitian one group pre test and post test design dimana dalam rancangan ini terdapat hanya satu kelompok objek yaitu kelompok eksperimen sebagai kelompok yang dikenakan perlakuan. Dalam penelitian ini yang menjadi sampel adalah anak 
usia 5-6 tahun di kelas B PAUD Al Hikmah berjumlah 15. Karena penelitian menggunakan konseling perlakuan penelitian, maka menggunakan metode purposive sampling yaitu metode penentuan sampel dengan pertimbangan khusus sehingga layak dijadikan sampel (Lumonggo, 2016). Instrumen yang digunakan dalam penelitian ini adalah lembar observasi dan dokumentasi. Adapun teknik analisis data yang diguanakan yakni analisis statistik dengan rumus t-test.

\section{Hasil Penelitian dan Pembahasan}

Pada penelitian ini, data yang diperoleh melalui dianalisis dengan menggunakan rumus $t$-test, akan tetapi sebelum data-data tersebut dianalisis menggunakan rumus statistik $t$ test, terlebih dahulu melakukan tabulasi atas data yang sudah terkumpul. Menyusun tabel deviasi pre-test dan post-test dimaksudkan untuk mengetahui deviasi yang diperoleh sebelum dan sesudah penerapan teknik behavior. Cara menyusun tabel deviasi pre-test dan post-test lebih jelasnya dapat dilihat pada tabel dibawah:

Tabel 1. Tabel Deviasi Pre-Test dan Post-Test

\begin{tabular}{|c|c|c|c|c|c|c|}
\hline No & Subyek & Y1 & Y2 & D(y2-y1) & $\begin{array}{c}\text { d } \\
(\mathbf{D}-\mathbf{M d})\end{array}$ & $\mathbf{d 2}$ \\
\hline$(1)$ & $(2)$ & $(3)$ & $(4)$ & $(5)$ & $(6)$ & $(7)$ \\
\hline 1 & AR & 20 & 35 & 15 & 0,6 & 0,36 \\
\hline 2 & MR & 20 & 33 & 13 & $-1,4$ & 1,96 \\
\hline 3 & YH & 30 & 45 & 15 & 0,6 & 0,36 \\
\hline 4 & LSM & 30 & 43 & 13 & $-1,4$ & 1,96 \\
\hline 5 & LZYK & 30 & 40 & 10 & $-4,4$ & 19,36 \\
\hline 6 & BHM & 30 & 43 & 13 & $-1,4$ & 1,96 \\
\hline 7 & BMN & 20 & 37 & 17 & 2,6 & 6,76 \\
\hline 8 & BM & 20 & 35 & 15 & 0,6 & 0,36 \\
\hline 9 & AYP & 20 & 37 & 17 & 2,6 & 6,76 \\
\hline 10 & BNR & 30 & 43 & 13 & $-1,4$ & 1,96 \\
\hline 11 & SY & 30 & 45 & 15 & 0,6 & 0,36 \\
\hline 12 & PA & 30 & 43 & 13 & $-1,4$ & 1,96 \\
\hline 13 & MRA & 30 & 43 & 13 & $-1,4$ & 1,96 \\
\hline 14 & ACP & 30 & 47 & 17 & 2,6 & 6,76 \\
\hline 15 & NS & 30 & 47 & 17 & 2,6 & 6,76 \\
\hline & TOTAL & 400 & $\mathbf{6 1 6}$ & $\mathbf{2 1 6}$ & $\mathbf{0 , 0}$ & $\mathbf{5 9 , 6}$ \\
\hline
\end{tabular}

Dari tabel kerja tersebut di atas, maka dapat dihitung nilai t-tes sebagai berikut :

MMd =14, 4

$$
\begin{aligned}
\mathrm{T} & =\frac{M d}{\sqrt{\frac{\sum \cdot d^{2}}{N(N-1)}}} \\
& =\frac{14,4}{\sqrt{0,28}} \\
& =\frac{26,6-41,0}{\sqrt{\frac{46}{15(15-1)}}}=\frac{14,4}{0,52}=\frac{14,4}{\sqrt{\frac{59,6}{210}}}=27,69
\end{aligned}
$$


Dengan menggunakan media bahan bekas anak dapat meningkatkan beberapa aspek perkembangan motorik halus yang dapat dikembangakan seperti membuat garis horizontal, garis vertikal, menggunting pola, menempel, menjiplak, menggunting dengan ukuran yang sama. Penggunana Bahan Bekas menurut Rusman dkk (2012) dapat; Sebagai alat bantu dalam proses pembelajaran, Sebagai komponen dari subsistem pembelajaran, Pembelajaran merupakan suatu system di mana di dalamnya terdapat sub-sub komponen di antaranya adalah media pembelajaran, Sebagai pengarah dalam pembelajaran, Sebagai permainan atau membangkitkan perhatian dan motivasi anak, dan Meningkatkan hasil dari proses pembelajaran. Dengan demikian Media bahan bekas sangat bermamfaat sekali disamping bisa dikreasikan juga bisa mengurangi limbah sampah, dan mempunyai peranan yang positf dalam meningkatkan aspek perkembangan anak, namun yang lebih penting lagi sangat berpengaruh pada aspek perkembangan Motorik Halus anak pada usia 5-6 Tahun, dan secara lebih luas anak dapat mengembangkan seluruh aspek perkembangan anak seperti anak dapat bersosialisasi dengan teman, guru dan lingkungannya tanpa ada rasa malu dan takut dan dapat juga melatih anak dalam memecahkan masalah. Hal ini sejalan dengan pendapat Hurlock (2013) Keterampilan motorik halus yaitu: Kemampuan menggunakan otot-otot halus yang melibatkan koordinasi antara mata dan tangan. Pengendalian otot tangan, bahu,dan pergelangan tangan meningkat dengan cepat selama masa kanak-kanak dan pada usia 12 tahun anak hampir mencapai tingkat kesempurnaan seperti orang dewasa.

Dari teori yang telah diajukan dalam pembahasan tersebut yang selanjutnya dibandingkan dengan hasil analisa data yang diperoleh melalui penelitian dengan menggunakan analisis statistic dengan rumus t-test, ternyata hipotesis nol (Ho) yang berbunyi: Tidak ada pengaruh bermain menggunakan bahan bekas terhadap keterampilan motorik halus anak usia 5-6 tahun di PAUD Al Hikmah di tolak, dan hipotesis alternative (Ha) yang berbunyi: Ada Pengaruh bermain menggunakan Bahan Bekas terhadap keterampilan motorik halus anak usia 5-6 tahun di PAUD Al Hikmah di terima. Dalam penelitian ini diperoleh hasil sebesar 30,7 sedangkan pada t-table 2,145, ini menunjukan bahwa hasil penelitian yang positif. Hal ini dikarenakan pada usia anak 5-6 tahun keterampilan motorik halus anak sudah sempurna.

Berdasarkan pembahasan data dari penelitian diatas dapat disimpulkan bahwa dalam mengembangkan motorik halus anak melalui pemamfaatan media bahan bekas dalam pelaksanaannya yang pertama kali ialah guru perlu melakukan persiapan, melakukan kegiatan pelaksanaan, dan melakukan pengamatan agar dapat mengetahui perkembangan yang telah dicapai masing-masing anak. Melakukan pembelajaran dengan memamfaatkan bahan bekas yang dapat dijadikan hiasan jendela dari sedotan bekas,bingkai poto dari stik es krim,dan mobil-mobilan dari bekas kotak pepsodent, menggunakan langkah-langkah yang sesuai maka akan dapat menstimulus perkembangan motorik halus anak menjadi lebih baik, anakpun telah mampu menggunakan gunting dengan baik, bahkan anak mampu memegang pensil dengan benar.

\section{Kesimpulan}

Kesimpulan yang diperoleh dari penelitian ini adalah terdapat pengaruh media bahan bekas terhadap keterampilan motorik halus anak usia dini di PAUD Al Hikmah. Dalam penelitian ini diperoleh hasil sebesar 30,7 sedangkan pada t-table 2,145, hal ini menunjukan bahwa terdapat pengaruh yang positif. 


\section{Saran}

Adapun saran yang dapat disampaikan berdasarkan hasil penelitian ini adalah; (1) Guru sebaiknya meningkatkan intensitas penggunaan barang-barang bekas dalam kegiatan pembelajaran agar anak dapat termotivasi dalam mengikuti kegiatan yang diberikan guru. (2) Guru sebaiknya hanya mendampingi anak dan memberikan pengarahan atau contoh ketika membuat mobil-mobilan, hiasan jendela, dan bingkai foto, beri kesempatan anak untuk bereksplorasi menciptakan bentuk yang sudah di contohkan oleh guru.

\section{Daftar Pustaka}

Agus Abdurahman. (2013). Pisikologi Sosial. Jakarta: PT RajaGafindo Persada

Alit Suarti, N. (2020). BERMAIN PUZZLE MEMUPUK SIKAP KEMANDIRIAN PADA ANAK USIA DINI. Jurnal Paedagogy, 2(1), 13-21. doi:https://doi.org/10.33394/jp.v2i1.3044

Endriani, A. (2015). Studi Kemampuan Berkomunikasi Anak Usia Dini di TK Nurul Huda Selayar Sakra Barat Kabupaten Lombok Timur. Jurnal Kependidikan: Jurnal Hasil Penelitian dan Kajian Kepustakaan di Bidang Pendidikan, Pengajaran dan Pembelajaran, 1(2). doi:https://doi.org/10.33394/jk.v1i2.389

Hasnida. (2014). Analisis Kebutuhan Anak Usia Dini. PT.Luxima Metro Media Jakarta.

Hurlock, Elizabeth B. (2013). Child Development: Perkembangan Anak. Edisi ke enam. Diterjemahkan oleh: Meitasari Tjandrasa dan Muslichah Zarkasih. Erlangga: Jakarta.

Iskandar, Agus. (2006). Daur Ulang Sampah. Azka Mulia Media: Jakarta.

Jamaris, Martini. (2013). Orientasi Baru dalam Psikologi Pendidikan. Ghalia Indonesia: Bogor.

Kemdikbud. (2016). Memahami Pendidikan Anak Usia Dini. Diakses dari http://paud.kemdikbud.go.id/2016/03/30/memahami-pendidikan-anak-usia-dini/

Lumongga Lubis dan Hasnida. (2016). Konseling Kelompok. Jakarta: Kharisma Putra Utama.

Rabiah, R. (2020). PENGARUH BERMAIN PERAN TERHADAP KEMAMPUAN SOSIAL EMOSIONAL ANAK USIA 5-6 TAHUN DI TK AISYIYAH BUSTANUL ATHFAL 5 MATARAM. Jurnal Paedagogy, $\quad$ 1(1), 28-34. doi:https://doi.org/10.33394/jp.v1i1.3056

Selamet, I. (2020). Penggunaan Media Visual untuk Meningkatkan Hasil Belajar Mata Pelajaran IPS Siswa Kelas V SD Inpres Tumpu Jaya I. Jurnal Paedagogy, 7(2), 121125. doi:https://doi.org/10.33394/jp.v7i2.2505

Sri, S. N., Rizka, M. A., \& Maskun, M. (2018). Pengaruh Pelatihan Hypnoparenting Terhadap Peningkatan Pemahaman Orang Tua dalam Mendidik Anak Usia Dini di Desa Aikmual Kabupaten Lombok Tengah Tahun 2016. Transformasi: Jurnal Penelitian dan Pengembangan Pendidikan Non Formal Informal, 3(1).

Sumantri. (2005). Model Pengembangan Keterampilan Motorik Anak Usia Dini. Depdiknas: Jakarta.

Surodiana, S. (2020). Penerapan Media Permainan Sosiology Shot Traditional (SOSIS -T) untuk Meningkatkan Motivasi Belajar Sosiologi Siswa MAN 1 Lombok Timur. Jurnal Paedagogy, 7(4), 302-311. doi:https://doi.org/10.33394/jp.v7i4.2927 